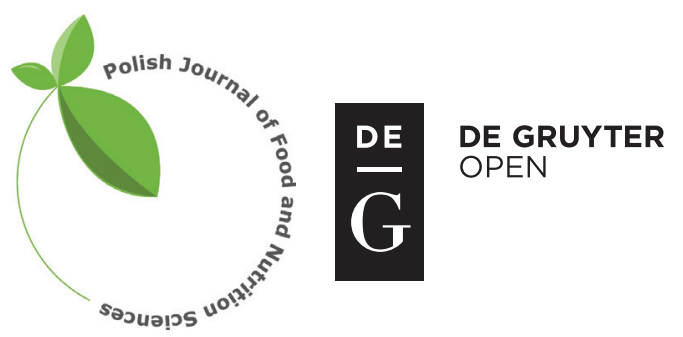

Pol. J. Food Nutr. Sci., 2016, Vol. 66, No. 4, pp. 277-285

DOI: $10.1515 /$ pjfns-2016-0008 http://journal.pan.olsztyn.pl

Original article

Section: Food Technology

\title{
Characterization of Starch Edible Films with Different Essential Oils Addition
}

\author{
Danijela Šuput ${ }^{1 *}$, Vera Lazić1 ${ }^{1}$ Lato Pezo ${ }^{2}$, Siniša Markov ${ }^{1}$, Žužana Vaštag ${ }^{1}$, Ljiljana Popović1, \\ Aleksandra Radulovic ${ }^{2}$, Sanja Ostojic $c^{2}$, Snežana Zlatanović2, Senka Popović ${ }^{1}$ \\ ${ }^{1}$ Faculty of Technology, University of Novi Sad, Bulevar Cara Lazara 1, 21000, Novi Sad, Serbia \\ ${ }_{2}^{2}$ Institute of General and Physical Chemistry, University of Belgrade, Studentski Trg 12, 11000, Belgrade, Serbia
}

Key words: bio-film, essential oils, starch

This study investigated properties of starch-based edible films with oregano and black cumin essential oil addition. Essential oils addition positively affected film swelling (decreased due to essential oil addition), mechanical properties (tensile strength decreased while elongation at break increased), and water vapor barrier properties (decreased along with essential oils addition). Control film did not have any biological activity, which proves the need for essential oils addition in order to obtain active packaging. Oregano oil was more effective in terms of biological activity. Endothermal peak, above $200^{\circ} \mathrm{C}$, represents total thermal degradation of edible films. Diffraction pattern of control film showed significant destruction of A-type crystal structure. Addition of essential oils resulted in peak shape change: diffraction peaks became narrower. Principal Component Analysis has been used to assess the effect of essential oils addition on final starch-based edible films characteristics with the aim to reveal directions for the film characteristics improvement, since the next phase will be optimal film application for food packaging.

\section{INTRODUCTION}

Starch is commonly used for packaging application as it can be readily cast into edible films. Starch films are tasteless, odorless, flexible and transparent [Muller et al., 2009; Bilbao-Sainz et al., 2010] and as such prevent taste, flavor and appearance change of food products [Chiumarelli \& Hubinger, 2012]. Main advantages of starch films are excellent barrier properties to gasses and delayed aroma and solutes transmission [Goni et al., 2009]. On the other hand, starch based edible film's biggest flaw is high permeability to water vapor transfer [Falguera et al., 2011], which might be overcome by the incorporation of lipid additives, waxes or essential oils, increasing hydrophobic fraction of the film [Sanchez-Gonzales et al., 2011].

Nowadays, rapid development in the functional food market leads to the emergence of active packaging [Campos et al., 2001], so synthetic preservatives and antioxidants have been substituted for substances marketed as natural which could be incorporated into film-forming solutions with aim to achieve active packaging function [Singh et al., 2014; Han, 2003].

Essential oils are aromatic oily liquids obtained from plant materials so they can be used in edible packaging application to promote antimicrobial and antioxidant activities [Nanasombat \& Wimuttigosol, 2011]. Chemical struc-

\footnotetext{
* Corresponding Author: Tel:+381214853702; Fax:+361216350262;

E-mail: suput.danijela@gmail.com (Danijela Z. Šuput)
}

ture, interactions and concentration of essential oil active components are directly related to their activity [Avila-Sosa et al., 2012]. Essential oils usage in food preservation might be limited due to possible changes in the sensory properties of the food [Sanchez-Gonzales et al., 2011] since sometimes effective doses may exceed sensory acceptable levels [Viuda-Martos et al., 2008]. A problem solution is essential oil incorporation within edible film matrix, which has the encapsulation effect. The effect is reflected in the minimized essential oil doses, limited volatilization and controlled release of active components from package surface [Salarbashi et al., 2013].

The aim of this work was to characterize starch-based edible films with essential oils addition regarding their physico-mechanical, barrier, structural, thermal, optical and biological (antioxidant and antimicrobial) properties. In order to enable more comprehensive comparison between investigated samples, Principal Component Analysis (PCA) has been applied to classify and discriminate the analyzed samples.

\section{MATERIALS AND METHODS}

\section{Reagents}

Modified corn starch (C*EmTex 12688) and guar-xanthan (Lygomme KTC 58) modified mixture were provided by Palco (Kolbermoor, Germany). Essential oils were obtained from Probotanic (Belgrade, Serbia). Glycerol was obtained from Laboratorija (Novi Sad, Serbia). 2.2-Diphenyl-1-picrylhydrazyl (DPPH) was purchased from Sigma-Aldrich Chemical 
(St. Louis, Missouri, USA), while Folin-Ciocalteu Reagent was purchased from Mol Beograd (Belgrade, Serbia).

\section{Film preparation}

Starch films were prepared by casting an aqueous modified maize starch solution $(1.5 \mathrm{mg} / \mathrm{mL})$. The solution was heated at $90^{\circ} \mathrm{C}$ for $60 \mathrm{~min}$ in a water bath. A weight of glycerol equal to $40 \%$ of the original starch was added and the solution was kept hot with mechanical stirring for 10 min more. Finally, the guar-xanthan modified mixture was added in a portion of $0.1 \%$ to initial starch weight. Two essential oils were added: black cumin oil (BC) and oregano oil $(\mathrm{O})$ in contents of $0.5 \%$, $1 \%$ and $2 \%$. Samples were labeled as BC $0.5 \%, \mathrm{BC} 1 \%$, BC $2 \%, \mathrm{O} 0.5 \%, \mathrm{O} 1 \%$ and $\mathrm{O} 2 \%$. Starch edible film without essential oil was used as control (C). The film-forming solution was homogenized using a homogenizer at $166.67 \mathrm{~Hz}$ for $1 \mathrm{~min}$ and then degassed under vacuum to remove dissolved air. The film-forming solution $(50 \mathrm{~g})$ was directly cast into Petri dishes and left to air-dry on a leveled surface at room temperature $\left(25 \pm 2^{\circ} \mathrm{C}\right)$ for 5 days after which it was analyzed.

\section{Physical properties}

Film thickness was measured using a micrometer with sensitivity of $1 \mu \mathrm{m}$. Ten thickness measurements were carried out on each film.

Water content $\left(W_{\mathrm{C}}\right)$ was determined as the percentage of initial film weight loss during drying and reported on a wet basis, Eq. (1):

$$
W_{C}=100 \times \frac{w_{1}-w_{2}}{w_{1}}
$$

Film samples $(1 \times 1 \mathrm{~cm})$ were weighed $\left(w_{1}\right)$, dried at $105^{\circ} \mathrm{C}$ for $24 \mathrm{~h}$ and weighed again $\left(w_{2}\right)$. Swelling was determined by the modified method described by Bigi et al. [2001]. The amount of adsorbed water was calculated according to Eq. 2 and expressed as percentage:

$$
W=100 \times \frac{W_{w}-W_{d}}{W_{d}}
$$

where: $W_{\mathrm{w}}$ and $W_{\mathrm{d}}$ are the weights of the wet and air-dried samples.

\section{Mechanical properties}

Tensile strength (TS) and elongation to break (EB) were measured on the Instron Universal Testing Instrument Model No 4301 (Instron Engineering, Canton, Massachusetts, USA), according to the standard method EN ISO 527-3:1995. Film samples were cut into rectangular strips $(15 \times 90 \mathrm{~mm})$. The initial grip separation was set at $50 \mathrm{~mm}$, and crosshead speed was set at $50 \mathrm{~mm} / \mathrm{min}$. TS and EB measurements for each sample were repeated eight times.

\section{Water vapor barrier properties}

Water vapor barrier properties of films were determined gravimetrically according to the standard method ISO
2528:1995. Three replicates of each sample were tested simultaneously.

\section{X-Ray Diffraction (XRD) measurements}

The X-ray diffraction patterns were recorded on a Philips PW-1710 automated diffractometer (Philips Industrial \& Electron-acoustic Systems Division, Almelo, The Netherlands) using a $\mathrm{Cu}$ tube operated at $40 \mathrm{kV}$ and $30 \mathrm{~mA}$. The instrument was equipped with a diffracted beam curved graphite monochromator and an Xe-filled proportional counter. Diffraction data were collected in $2 \theta$ range $4-70^{\circ}$, with counting time of $0.5 \mathrm{~s}$ per step and a step size of $0.02^{\circ} 2 \theta$. Fixed $1^{\circ}$ divergence and $0.1 \mathrm{~mm}$ receiving slits were used.

\section{Thermal analysis}

Differential scanning calorimetry (DSC) of edible film samples was performed on TA Instruments DSC Q 1000, (TA Instruments, New Castle, Delaware, USA), under high purity $(99.999 \%) \mathrm{N}_{2}$ purge flow of $50 \mathrm{~mL} / \mathrm{min}$. Samples of $1-2 \mathrm{mg}$ were weighed in aluminum pans and were hermetically sealed; an empty pan was used as reference. DSC scans were conducted in temperature range from -90 to $250^{\circ} \mathrm{C}$, with a heating rate of $\mathrm{Hr}=5^{\circ} \mathrm{C} / \mathrm{min}$.

\section{Optical properties}

The instrumental surface color of film samples was measured, in triplicate, by a Konica Minolta Chroma Meter CR400 (Minolta, Osaka, Japan). Results were expressed as lightness $\left(L^{*}\right)$, redness-greenness $\left(a^{*}\right)$ and yellowness-blueness $\left(b^{*}\right)$. The total difference in color $\left(\Delta E^{*}\right)$ was calculated according to the following equation:

$$
\Delta E^{*}=\sqrt{\left(\Delta L^{*}\right)^{2}+\left(\Delta a^{*}\right)^{2}+\left(\Delta b^{*}\right)^{2}}
$$

where: $\Delta L^{*}, \Delta a^{*}$ and $\Delta b^{*}$ are the differences between the corresponding sample color parameter and white standard $\left(L^{*}=97.00 ; a^{*}=0.12 ; b^{*}=2.06\right)$.

The ultraviolet (UV) and visible light barrier properties of the films were measured at selected wavelengths from $200 \mathrm{~nm}$ to $800 \mathrm{~nm}$ using a T80 UV-Vis spectrophotometer (PG instruments, Leicestershire, United Kingdom).

\section{Biological activity}

Antioxidant activity

Antioxidant activity $(A A)$ of the films was assessed on the basis of scavenging the stable $\mathrm{DPPH} \cdot$ free radical according to the assay described by Morales \& Jimenez-Perez [2001] with modifications: $100 \mathrm{mg}$ of film was placed in a flask containing $2.4 \mathrm{~mL}$ of $0.16 \times 10^{-3} \mathrm{~mol} / \mathrm{L}$ ethanol solution of $\mathrm{DPPH}^{*}$ and was stirred for $1 \mathrm{~h}$ and $2.5 \mathrm{~h}$, in a dark chamber at room temperature. The controls did not contain the films. In each sample, the remaining $\mathrm{DPPH}{ }^{*}$ concentration was determined after removing the solid film and measuring the absorbance at $520 \mathrm{~nm}$ using a T80 UV-Vis spectrophotometer. The $A A$ of the films was expressed as a percentage and calculated following the formula: 


$$
A A(\%)=\left(1-\left[D P P H^{\bullet}\right]_{t} /\left[D P P H^{\bullet}\right]_{C}\right) \times 100
$$

where: $\left[\mathrm{DPPH}^{*}\right]_{\mathrm{t}}$ is the concentration of $\mathrm{DPPH}^{\bullet}$ in the tested sample and $\left[\mathrm{DPPH}^{*}\right]_{\mathrm{c}}$ is the concentration of $\mathrm{DPPH}^{*}$ in the respective blank.

\section{Total phenolic content (TP)}

The total phenolic content (TP) was determined according to the Folin-Ciocalteu reagent as described by Singleton et al. [1999] with modifications. Briefly, $0.1 \mathrm{~mL}$ of a water film extract solution were mixed with $7 \mathrm{~mL}$ of distilled water and $0.5 \mathrm{~mL}$ of the Folin-Ciocalteu reagent. The mixture was incubated for $8 \mathrm{~min}$ at room temperature before addition of $1.5 \mathrm{~mL}$ of $\mathrm{NaCO}_{3}$ solution and $0.9 \mathrm{~mL}$ of distilled water. The mixture was stored in a dark chamber at room temperature for $2 \mathrm{~h}$. The absorbance of the mixture was then measured at $765 \mathrm{~nm}$ using a T80 UV-Vis spectrophotometer. Gallic acid solutions in the specific concentration range were used to construct a calibration curve.

\section{Antimicrobial characteristics}

The disk-diffusion assay was used to examine the antimicrobial characteristics of the films, three times for each strain. Film samples were cut into discs $6 \mathrm{~mm}$ in diameter using a sterile punch and these were then placed on plates containing Mueller-Hinton agar (MHA) which had been previously seeded with $100 \mu \mathrm{L}$ of an overnight broth culture containing approximately $10^{5} \mathrm{CFU} / \mathrm{mL}$ of the test bacteria. The films were tested for their inhibition against Escherichia coli ATCC 25922, Listeria monocytogenes ATCC 19111 and Salmonella Typhimurium ATCC 14028. The plates were incubated at $37^{\circ} \mathrm{C}$ for $24 \mathrm{~h}$ and the clear zone formed around the film disc on the media was recorded. Simultaneously, antibacterial tests were done with control film and control film coated with antibiotic (cetofaxim+clavulanic acid, $40 \mu \mathrm{g} /$ disk) (Bioanalyse ${ }^{\circledast}$, Ankara, Turkey).

\section{Statistical analysis}

All data were subjected to the analysis of variance (ANOVA) for the comparison of means, and significant differences were calculated according to post-hoc Tukey's HSD test at a significance level of $p<0.05,95 \%$ confidence limit, using the STATISTICA 10.0 software (StatSoft, Tulsa, Oklahoma, USA). All samples were analyzed in triplicate. Principal Component Analysis (PCA) has been applied to classify and discriminate different samples of starch-based edible films with essential oils addition. Pattern recognition technique has been applied within results descriptors to characterize and differentiate all observed samples.

\section{RESULTS AND DISCUSSION}

\section{Physical properties}

According to visual examination, the obtained films were transparent, odorless, easy to handle. Film thickness varied from $101.10 \mu \mathrm{m}$ to $111.40 \mu \mathrm{m}$ and incorporation of essential oils did not significantly affect the resulting film thickness $(p>0.05)$. Very small values of standard deviation proved film uniformity, no matter films are biologically active materials.
The swelling in water of the prepared starch films with/ without essential oils is presented in Table 1. According to Kavoosi et al. [2013], it is expected that hydrophilic compounds should increase film's swelling, whereas hydrophobic compounds should decrease it. Results proved that essential oil addition decreased swelling while control film swelling was the highest. The present study results proved that the film swelling capacity followed the same trend as moisture content which is in accordance with other findings [Ghasemlou et al., 2013; Fabra et al., 2010].

\section{Mechanical properties}

Results related to mechanical properties are shown in Figure 1a and Figure 1b. TS value of the control film was 14.43 MPa, while TS of the films with $\mathrm{BC}$ addition decreased from 10.02 MPa to 2.3 MPa and TS of the films with $\mathrm{O}$ addition decreased from 10.65 MPa to 2.12 MPa. Figure 1a shows that both essential oils decreased TS values indicating loss of macromolecular mobility, which is in accordance with findings of Souza et al. [2013]. Plasticizing capacity of essential oils caused reduction of the TS [Pelissari et al., 2009]. Mechanical properties are improved by essential oils addition, which has a plasticizing effect attracting water molecules. As a result, interactions between starch and essential oils occurs instead between starch molecules. The formed complex structures reduced the cohesion forces of a starch network, thereby decreasing TS values [Jimenez et al., 2013].

Elongation at break values of the tested films increased from $38 \%$ to $52 \%$ for the samples with $\mathrm{BC}$ addition and also increased from $32 \%$ to $61 \%$ for the samples with $\mathrm{O}$ addition while EB value for the control film was $28 \%$. Figure $1 \mathrm{~b}$ shows that the addition of both essential oils increased EB values, which is in accordance of other author findings [Ghasemlou et al., 2013; Benavides et al., 2012]. TS values decline and EB values increase are the most common results of essential oil incorporation in biopolymer matrices.

\section{Water vapor permeability}

Water vapor transfer (WVT) occurs through the hydrophilic portion of the film. Since glycerol is a hydrophilic mole-

TABLE 1. Physical properties of starch-based edible films with essential oils.

\begin{tabular}{l|c|c|c}
\hline Sample & $\begin{array}{c}\text { Thickness } \\
(\mu \mathrm{m})\end{array}$ & $\begin{array}{c}\text { Moisture } \\
\text { content }(\%)\end{array}$ & $\begin{array}{c}\text { Swelling } \\
\text { in water }(\%)\end{array}$ \\
\hline C & $101 \pm 4^{\mathrm{a}}$ & $14.1 \pm 1.3^{\mathrm{a}}$ & $231 \pm 2^{\mathrm{g}}$ \\
BC 0.5\% & $106 \pm 3^{\mathrm{b}}$ & $12.9 \pm 0.9^{\mathrm{a}}$ & $209 \pm 2^{\mathrm{f}}$ \\
BC 1\% & $109 \pm 4^{\mathrm{bc}}$ & $12.1 \pm 1.2^{\mathrm{a}}$ & $175 \pm 2^{\mathrm{d}}$ \\
BC 2\% & $110 \pm 3^{\mathrm{bc}}$ & $12.2 \pm 0.5^{\mathrm{a}}$ & $130 \pm 2^{\mathrm{b}}$ \\
O 0.5\% & $108 \pm 4^{\mathrm{b}}$ & $13.1 \pm 1.0^{\mathrm{a}}$ & $197 \pm 2^{\mathrm{e}}$ \\
O 1\% & $111 \pm 4^{\mathrm{c}}$ & $12.3 \pm 0.8^{\mathrm{a}}$ & $156 \pm 1^{\mathrm{c}}$ \\
O 2\% & $110 \pm 5^{\mathrm{bc}}$ & $12.0 \pm 1.2^{\mathrm{a}}$ & $118 \pm 1^{\mathrm{a}}$ \\
\hline
\end{tabular}

a-g Different letters printed in superscript within the same column in the table show significantly different means of the observed data (at $p<0.05$ level). 

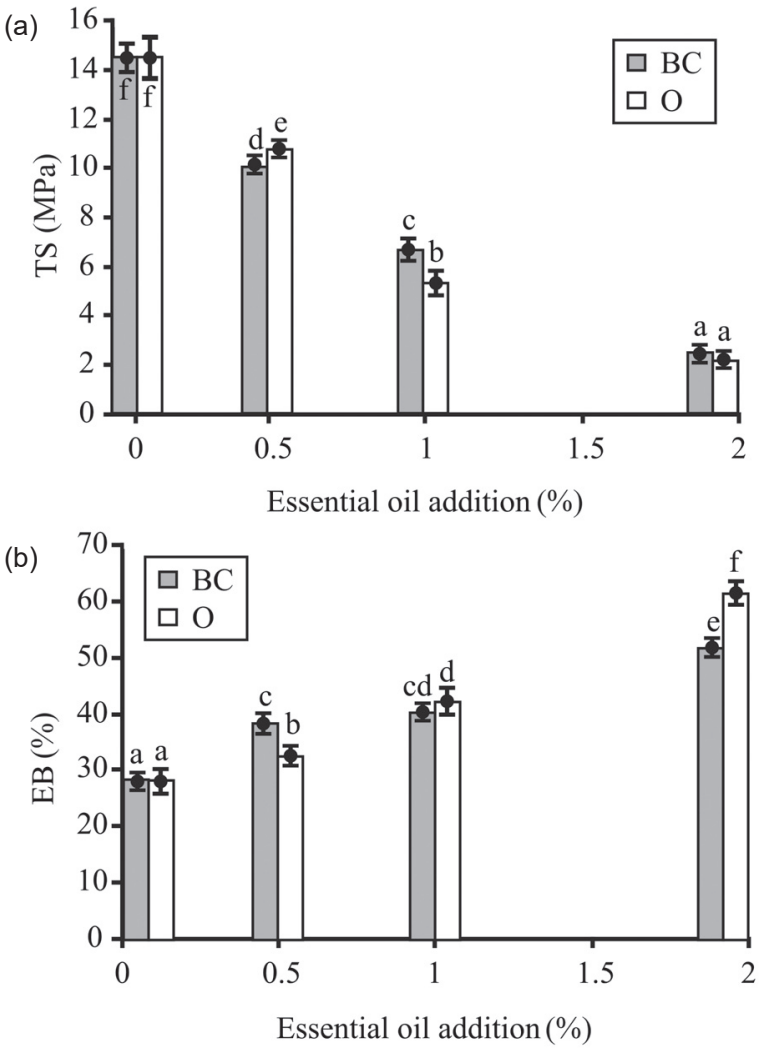

FIGURE 1. Mechanical properties of starch-based edible films with essential oils, a) tensile strength, b) elongation at break.

Different letters (a-f) show significantly different means of the observed data $(p<0.05)$, according to the post hoc Tukey's HSD test.

cule which decreases intermolecular attractions and increases molecular mobility [Rodriguez et al., 2006], it was expected that the control film had highest water vapor permeability $\left(8.58 \mathrm{~g} /\left(\mathrm{m}^{2} \cdot \mathrm{h}\right)\right)$. Essential oils addition into the film-forming solution decreased WVT, which could be seen in Figure 2. Films prepared with both essential oils showed lower moisture content than the control film and these decreased significantly $(p<0.05)$ as essential oil addition increased. This WVT value decrement is consistent with the results of previous studies [Kechichian et al., 2010; Shojaee-Aliabadi et al., 2013]. Still, final WVT values are not satisfactory, so further step should involve the optimization of film composition with lipids (waxes) in order to increase the resistance to water vapor permeability [Mehyar et al., 2012].

\section{XRD measurements}

Crystallinity of starch is related to amylopectin linear chains which may give different X-ray diffraction patterns depending on starch source [Buleon et al., 1997]. Film preparation by casting procedure usually leads to solubilization of amylose followed by destruction of starch crystalline structure [Parker \& Ring, 2001]. Diffraction patterns of the control starch film and starch films with BC and $\mathrm{O}$ essential oil addition in different contents are given in Figure 3(a-g). Diffraction pattern of the control film showed a broad diffraction peak in $15-20^{\circ} 2 \theta$ region, indicating destruction of A-type crystal structure due to experimental conditions of the casting procedure used in this work. Addition of BC resulted in a change in peak shape: diffraction peaks became narrower. Discussed peaks in XRD patterns with BC addition (Figure 3(b-d)) are centered at $19.8^{\circ}, 20.4^{\circ}$ and $20.1^{\circ} 2 \theta$ respectively, while the pattern of sample BC $1 \%$ showed additional diffraction peaks at $30.1^{\circ}, 38.5^{\circ}, 44.5^{\circ}$ and $64.82 \theta$. In the case of diffraction patterns of starch films with $\mathrm{O}$ oil addition, narrowing of the main diffraction peak is also observed but it is not as pronounced as in the case of starch films with BC addition. Diffraction peaks of samples with $\mathrm{O}$ addition (Figure 3(e-g)) whose shapes are to some extent retained after oregano oil addition, are centered at $20.8^{\circ}, 20.1^{\circ}$ and $21.6^{\circ} 2 \theta$ respectively, while pattern of sample $\mathrm{O} 2 \%$ showed additional diffraction peaks at $31.1^{\circ}, 35.1^{\circ}, 38.3^{\circ}, 44.5^{\circ}$ and $64.92 \theta$.

Additional diffraction peaks detected in XRPD patterns of sample BC $1 \%$ (Figure 3 (c)) and sample O 2\% (Figure 3 (g)) could correspond to the process-induced crystallinity. The discussed peaks were not further investigated from the crystallographic point of view in this contribution and will be the subject of investigation in the next publication.

\section{Thermal analysis}

The obtained DSC results point to one predominating broad endothermal peak characteristic for all film samples in the temperature range between $65^{\circ} \mathrm{C}$ and $190^{\circ} \mathrm{C}$, which is a consequence of incomplete starch gelatinization during film production [Mali et al., 2002] and water evaporation. The second endothermal peak occurs at temperatures above $200^{\circ} \mathrm{C}$, and corresponds to the complete thermal degradation of the film [Nobrega et al., 2012]. Differences in the enthalpy $(\Delta H)$, onset temperature $\left(T_{\mathrm{o}}\right)$ and temperature maximum $\left(T_{\mathrm{m}}\right)$ of thermal transition are noticeable considering different levels of essential oils addition (Table 2). There is a common trend in $\Delta H, T_{\mathrm{o}}$ and $T_{\mathrm{m}}$ decrease, considering the addition of both oils, which means that films with essential oils have reduced overall thermal stability compared to the control. This trend is slightly more pronounced considering the addition of $\mathrm{BC}$. An exception is the edible film with $\mathrm{O} 0.5 \%$ addition, where thermal stability decrease is minimally emphasized (stability lowered by about $10 \%$, compared to the control sample). Characteristic glass transition $\left(T_{\mathrm{g}}\right)$ of starch films was found in a temperature range of $14^{\circ} \mathrm{C}$ to $21^{\circ} \mathrm{C}$, which is in accor-

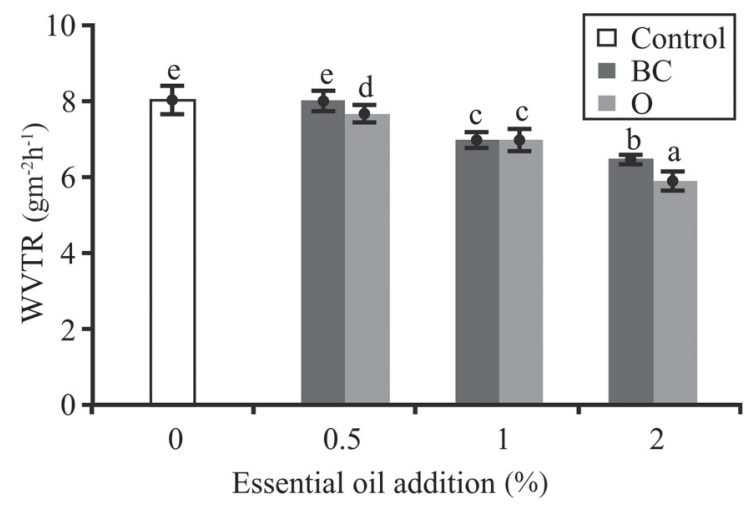

FIGURE 2. Water vapor transmission rate of starch-based edible films with essential oils.

Different letters (a-f) show significantly different means of observed data $(p<0.05)$, according to the post hoc Tukey's HSD test. 

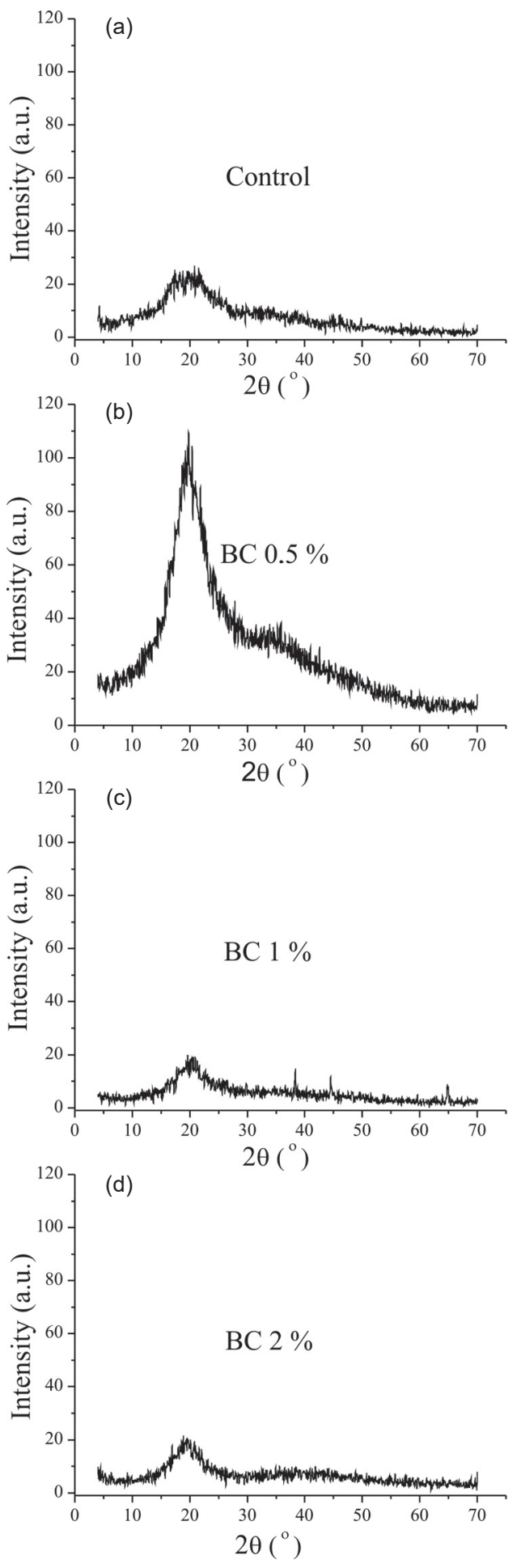

FIGURE 3. XRD patterns of starch-based edible films with essential oils

dance to literature data [Ghasemlou et al., 2011; Mali et al., 2006]. Essential oils addition causes glass transition temperature increase compared to the control. It may be concluded that the addition of essential oils to edible film has a similar effect as a plasticizer, i.e. it increases glass transition $\left(T_{\mathrm{g}}\right)$, because it facilitates chain mobility [Mali et al., 2006].

\section{Optical properties}

The color characteristics are presented in Table 3. The obtained films were transparent. The $L^{*}$ value $(0=$ black,
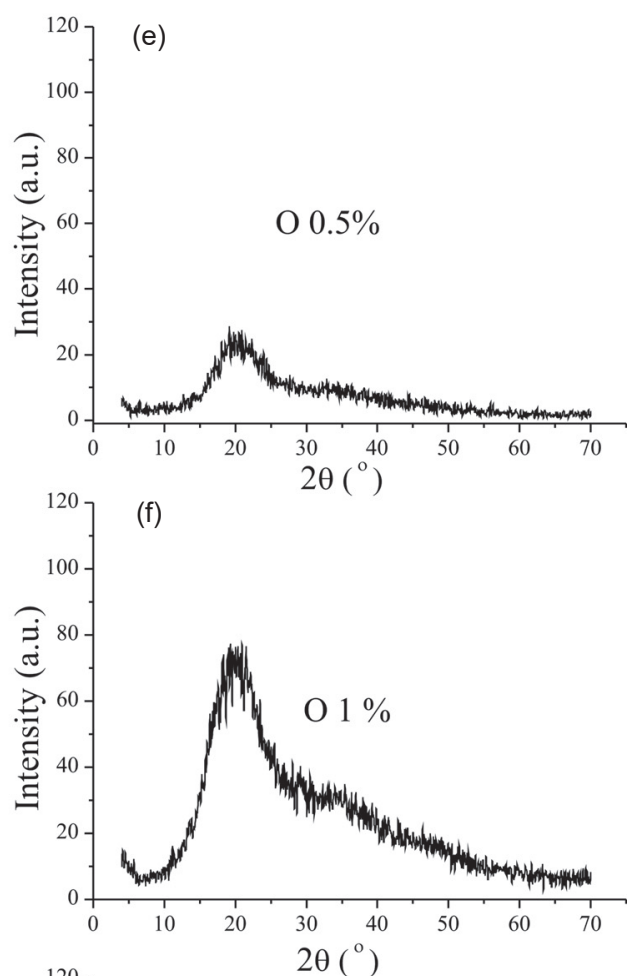

(g)

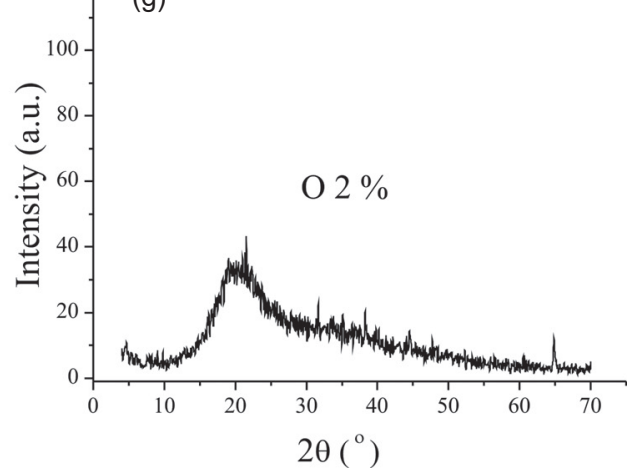

$100=$ white) was the most pronounced in the control film (95.32), while decreased when the oils were added. The $L^{*}$ value also proves that both oils addition in a higher content (2\%) caused less transparency of the film samples, hence the films became more opaque. For all samples and control film, the $a^{*}$ value was negative which means that the samples were slightly greenish. Film samples with $\mathrm{BC}$ addition had lower values of $a^{*}$ color parameter. In turn, the $b^{*}$ value was positive for all samples and control film and reached the highest value in the group of samples with BC addition. Green- 
TABLE 2. Thermodynamic parameters of starch-based edible films with essential oils.

\begin{tabular}{|c|c|c|c|c|c|c|c|}
\hline \multirow{2}{*}{ Sample } & \multicolumn{3}{|c|}{ The first peak } & \multicolumn{3}{|c|}{ The second peak } & \multirow{2}{*}{$\mathrm{T}_{\mathrm{g}}\left({ }^{\circ} \mathrm{C}\right)$} \\
\hline & $\Delta \mathrm{H}_{1}(\mathrm{~J} / \mathrm{g})$ & $\mathrm{T}_{\mathrm{ol}}\left({ }^{\circ} \mathrm{C}\right)$ & $\mathrm{T}_{\mathrm{m} 1}\left({ }^{\circ} \mathrm{C}\right)$ & $\Delta \mathrm{H}_{2}(\mathrm{~J} / \mathrm{g})$ & $\mathrm{T}_{\mathrm{o} 2}\left({ }^{\circ} \mathrm{C}\right)$ & $\mathrm{T}_{\mathrm{m} 2}\left({ }^{\circ} \mathrm{C}\right)$ & \\
\hline $\mathrm{C}$ & $141 \pm 10^{\mathrm{f}}$ & $70.6 \pm 5.7^{\mathrm{d}}$ & $199 \pm 10^{\mathrm{d}}$ & - & - & - & $14.8 \pm 0.6^{\mathrm{a}}$ \\
\hline BC $0.5 \%$ & $108 \pm 7^{\mathrm{d}}$ & $79.6 \pm 5.3^{\mathrm{e}}$ & $129 \pm 2^{c}$ & - & - & - & $16.4 \pm 0.8^{\mathrm{b}}$ \\
\hline $\mathrm{BC} 1 \%$ & $62 \pm 3^{a}$ & $69.2 \pm 3.2^{\mathrm{d}}$ & $116 \pm 5^{\mathrm{ab}}$ & - & - & - & $21.9 \pm 1.2^{\mathrm{d}}$ \\
\hline BC $2 \%$ & $78 \pm 4^{b}$ & $63.4 \pm 2.5^{\mathrm{a}}$ & $107 \pm 6^{\mathrm{a}}$ & 1.0 & 192 & 208 & $18.9 \pm 1.8^{c}$ \\
\hline O $0.5 \%$ & $132 \pm 8^{\mathrm{e}}$ & $68.7 \pm 1.0^{\mathrm{bc}}$ & $119 \pm 6^{\mathrm{b}}$ & - & - & - & $17.0 \pm 1.2^{\mathrm{b}}$ \\
\hline O $1 \%$ & $91 \pm 6^{c}$ & $66.6 \pm 2.1^{\mathrm{b}}$ & $118 \pm 9^{b}$ & - & - & - & $18.1 \pm 0.4^{c}$ \\
\hline $\mathrm{O} 2 \%$ & $107 \pm 3^{\mathrm{d}}$ & $67.2 \pm 3.6^{\mathrm{bc}}$ & $118 \pm 7^{b}$ & 17.2 & 189 & 224 & $18.2 \pm 0.4^{c}$ \\
\hline
\end{tabular}

a-g Different letters in superscript within the same column in the table show significantly different means of the observed data (at $p<0.05$ level). "-" No second peak has been detected on DSC curve for samples: C, BC $0.5 \%, \mathrm{BC} 1 \%, \mathrm{O} 0.5 \%$ and $\mathrm{O} 1 \%$.

TABLE 3. Mean values of color and light absorption of starch-based edible films with essential oils.

\begin{tabular}{l|c|c|c|c|c|c|c|c|c|c|c}
\hline \multirow{2}{*}{ Sample } & \multicolumn{4}{|c|}{ Color coordinates } & \multicolumn{6}{c}{ Light absorption (nm) } \\
\cline { 2 - 12 } & $L^{*}$ & $a^{*}$ & $b^{*}$ & $\mathrm{D} E^{*}$ & 200 & 280 & 350 & 400 & 500 & 600 & 800 \\
\hline C & 95.32 & -0.09 & 4.02 & 2.590 & 2.250 & 0.304 & 0.147 & 0.121 & 0.101 & 0.091 & 0.079 \\
BC 0.5\% & 95.28 & -0.66 & 6.41 & 4.742 & 3.177 & 0.492 & 0.137 & 0.104 & 0.087 & 0.082 & 0.077 \\
BC 1\% & 95.21 & -0.70 & 6.98 & 5.299 & 2.948 & 0.602 & 0.146 & 0.108 & 0.087 & 0.082 & 0.078 \\
BC 2\% & 93.25 & -0.72 & 9.69 & 8.543 & 3.305 & 1.562 & 0.360 & 0.215 & 0.138 & 0.117 & 0.104 \\
O 0.5\% & 95.24 & -0.16 & 5.28 & 3.677 & 9.999 & 1.884 & 0.469 & 0.360 & 0.330 & 0.323 & 0.313 \\
O 1\% & 95.14 & -0.31 & 6.47 & 4.694 & 9.999 & 1.703 & 0.497 & 0.406 & 0.384 & 0.367 & 0.326 \\
O 2\% & 91.36 & -0.41 & 7.39 & 7.778 & 9.999 & 2.905 & 0.631 & 0.447 & 0.412 & 0.394 & 0.360 \\
\hline
\end{tabular}

${ }^{*}$ Coefficients of variations for measured parameters were below $10 \%$ for all measurements. All samples were analyzed in triplicate.

ish color decreased and yellowish color increased as essential oil had been added, no matter which oil was added. The $\Delta E^{*}$ value showed a similar trend to changes in $b^{*}$ value which was expected since the samples are mostly yellowish [Ghasemlou et al., 2013].

Absorbance values increment is observed at wavelengths equal and less than $280 \mathrm{~nm}$, which corresponds to UV radiation. The smallest increment is observed for the control film and the largest in the group of samples with oregano oil added $(A=9.999$ for all samples at $200 \mathrm{~nm})$. Light absorption increases as essential oil addition increases in the range of 350-800 nm. Starch-based edible films with essential oils, added in sufficient quantity, could be used for packaging of food that is susceptible to oxidative changes catalyzed by UV light. Similar conclusions were obtained by Lopez et al. [2012] and Fang et al. [2002].

\section{Biological activity}

The total phenolics content (TP) and antioxidant activity (AA) values varied significantly, according to post-hoc Tukey's HSD (Table 4). The TP content in the film samples with BC oil ranged from 2.50 to $4.67 \mathrm{~g} / \mathrm{kg}$ and from 10.52 to $61.67 \mathrm{~g} / \mathrm{kg}$ for samples with $\mathrm{O}$ oil addition, expressed as gallic acid equivalents (GAE). Samples containing oregano oil showed a higher TP content so the activity of these samples was much higher, which is substantiated by the values of their antioxidant activity.

The $\mathrm{DPPH}^{\cdot}$ free radical scavenging assay proves that the analyzed substances could be scavengers of free radicals acting as hydrogen atom or electron donors [Jridi et al., 2013; Prior et al., 2005]. The antioxidant activity values in the samples with the addition of BC varied in the range of 5.5-12.4\%, and in the range of $23.8-87.7 \%$ for the samples with the $\mathrm{O}$ oil addition. As expected, the lowest AA (\%) was detected for the control film (1.6\%) whose total phenolic content was $2.66 \mathrm{~g} / \mathrm{kg}$ gallic acid equivalents (GAE). Most of the studies reported that the antioxidant activity of essential oils is caused mainly by phenolic compounds [Burt, 2004]. According to Viuda-Martos et al. [2007], major oil components of oregano included carvacrol $(61.2 \%)$, p-cymene $(15.1 \%)$, followed by $\gamma$-terpinene $(4.8 \%)$ identified by gas chromatography-mass spectrometry (GC-MS). On the other hand, GC-MS analysis revealed the major components in black cumin essential oils to be: thymoquinone (37.6\%), p-cymene $(31.2 \%)$, $\alpha$-thujene $(5.6 \%)$ and thymohydroquinone $(3.4 \%)$. Also, it was proved that all values of DPPH and TP were dose-dependent with essential oil addition, which is in agreement with other authors' findings [Oriani et al., 2014; Abdollahi et al., 2012]. 
TABLE 4. Biological activity (antioxidant and antimicrobial activity) of starch-based edible films with essential oils.

\begin{tabular}{|c|c|c|c|c|c|}
\hline \multirow{3}{*}{ Sample } & \multicolumn{2}{|c|}{ Antioxidant activity } & \multirow{2}{*}{\multicolumn{3}{|c|}{$\begin{array}{l}\text { Antimicrobial activity } \\
\text { Inhibition zone (mm) }\end{array}$}} \\
\hline & \multirow{2}{*}{$\begin{array}{c}\text { TP } \\
\text { (GAE equivalent ) }\end{array}$} & \multirow{2}{*}{$\begin{array}{l}\mathrm{AA} \\
(\%)\end{array}$} & & & \\
\hline & & & Salmonella Typhimurium & Escherichia coli & Listeria monocytogenes \\
\hline $\mathrm{C}$ & $2.7 \pm 0.0^{\mathrm{b}}$ & $1.6 \pm 0.0^{\mathrm{a}}$ & - & - & - \\
\hline BC $0.5 \%$ & $2.5 \pm 0.1^{\mathrm{a}}$ & $5.5 \pm 0.1^{\mathrm{b}}$ & - & - & - \\
\hline $\mathrm{BC} 1 \%$ & $3.1 \pm 0.0^{\mathrm{c}}$ & $8.7 \pm 0.1^{\mathrm{c}}$ & - & - & - \\
\hline BC $2 \%$ & 4. $7 \pm 0.1^{\mathrm{d}}$ & $12.4 \pm 0.1^{\mathrm{d}}$ & - & - & - \\
\hline O $0.5 \%$ & $10.5 \pm 0.1^{\mathrm{e}}$ & $23.8 \pm 0.7^{\mathrm{e}}$ & - & - & - \\
\hline O $1 \%$ & $38.1 \pm 0.4^{\mathrm{f}}$ & $59.3 \pm 1.6^{\mathrm{f}}$ & 12 & 22 & 37 \\
\hline $\mathrm{O} 2 \%$ & $61.7 \pm 0.2^{\mathrm{g}}$ & $87.7 \pm 0.4^{\mathrm{g}}$ & 33 & 37 & 39 \\
\hline Antibiotic & / & / & 20 & 21 & 13 \\
\hline
\end{tabular}

${ }^{\text {a-g }}$ Different letters in superscript within the same column in the table show significantly different means of the observed data (at $p<0.05$ level).

Many authors researched the effect of essential oils incorporation into a film-forming matrix regarding antimicrobial effects [Pelissari et al., 2009; Gniewosz et al., 2013; Oriani et al., 2014]. In these studies, the antimicrobial activity was expressed in terms of an inhibition zone. Inhibition areas yielded by starch-based edible film disks with different contents of $\mathrm{BC}$ and $\mathrm{O}$ oils against each studied microorganism are shown in Table 4. As expected, no inhibition zone against microorganisms was observed for the control. Even at minimum oregano oil addition applied into the film, inhibition occurred but the effect was not measurable. Below film disk there was inhibition while in the case of $\mathrm{BC}$ film samples no inhibition below film occurred [Souza et al., 2013]. BC compounds were inefficient to avoid microbial action. An analysis of the microbial activity of the edible films revealed the formation of the inhibition zone varying from $11.7 \mathrm{~mm}$ to $33 \mathrm{~mm}$ against S.typhimurium; from $22 \mathrm{~mm}$ to $37 \mathrm{~mm}$ against E.coli and from $12 \mathrm{~mm}$ to $39 \mathrm{~mm}$ against L.monocytogenes for the samples containing oregano essential oil in contents $1 \%$ and $2 \%$, respectively. Simultaneously, antibacterial tests were done with a disk coated with cetofaxim + clavulanic acid ( $40 \mu \mathrm{g} /$ disk) (Table 4). It can be observed that the oregano essential oil applied into the film matrix in the content of $2 \%$ had a stronger antimicrobial effect than the antibiotic.

Comparing the microorganisms, it can be concluded that Gram-positive bacteria are more sensitive to oregano oil since inhibition zone is larger. Although Gram-negative pathogens possess an outer membrane surrounding the cell wall that restricts diffusion of hydrophobic compounds, inhibition was accomplished when oregano oil was applied in the content of $1 \%$ and $2 \%$. As expected, a better inhibition was observed with a higher content of oregano oil.

\section{Principal component analysis}

The PCA allows considerable reduction in the number of variables and the detection of structure in the relationship between measuring parameters. The full auto scaled data matrix consisting of seven different mixtures with different technological treatments are submitted to PCA. For visualizing the data trends and the discriminating efficiency of the descriptors used, a scatter plot of samples using the first two principal components (PCs) issued from PCA of the data matrix is obtained (Figure 4). There is a neat separation of the seven trials. Quality results show that the first two principal components (PC), accounting for $83.62 \%$ of the total variability, can be considered sufficient for data representation. The variables: Thickness (10.8\% of the total variability), Moisture $(12.1 \%)$, Swelling $(11.6 \%), b^{*}(10.1 \%)$ and $\Delta E^{*}$ (10.4\%) have been found most influential for the first factor coordinate calculation, while the contribution of $\Delta H$ (explaining $11.0 \%$ of total variance), $a^{*}(16.8 \%), A A(22.4 \%)$ and $T P$ $(23.8 \%)$ have been most important variables for second factor coordinate calculation. The first PC is more influenced by the physical properties of samples, while the second PC is more impacted by antioxidant characteristics. The yellowness-blueness and the total lightness of the samples corresponded more to the physical properties, while the redness-greenness corresponded more to the second PC.

Essential oils addition influence shows that the samples with lesser oil addition have a higher water absorption and a higher moisture content. On the other hand, the sam-

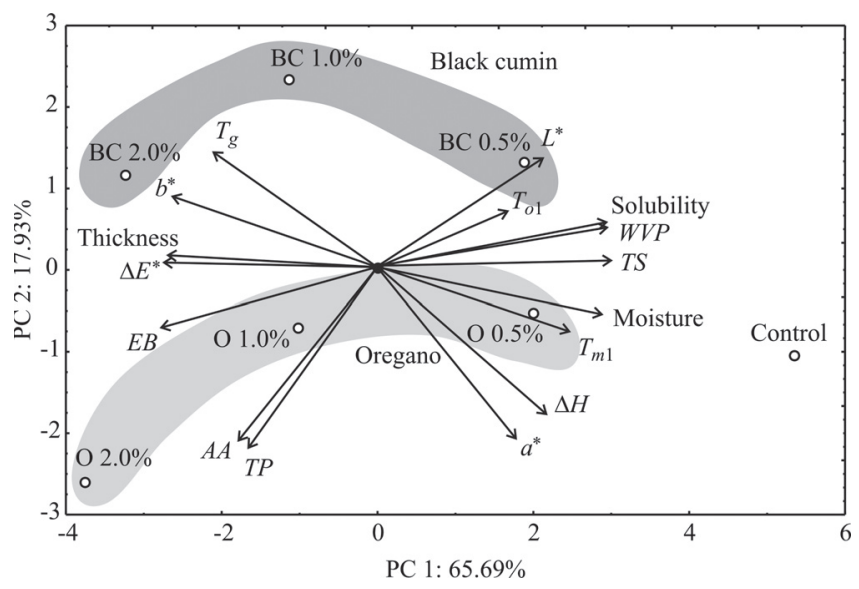

FIGURE 4. Biplot graphic of starch-based edible films with essential oils. 
ples having a higher essential oil content are thicker. The samples having a lesser essential oil content are lighter and reddish (samples with $0.5 \% \mathrm{BC}$ and $\mathrm{O}$ ), and the samples having a higher essential oil concentration are more yellowish (samples with $2 \% \mathrm{BC}$ and $\mathrm{O}$ ). The samples with no essential oil are more transparent. The samples with $\mathrm{O}$ showed better antioxidant characteristics and a higher TP content, compared to the samples with BC addition. The addition of essential oils reduced the thermal stability of starch-based films.

\section{CONCLUSIONS}

Nowadays, edible active films are in the focus of interest because of their many advantages and can be used as a supplement or a complete replacement of commercial polymers. This research was conducted with the objective to complete the knowledge of the active packaging based on starch. Essential oils were added to edible starch films to achieve active packaging. The impact of essential oil addition was observed regarding physico-mechanical, barrier, structural, thermal, optical and biological (antioxidant and antimicrobial) properties. It was shown that the addition of oils contributes significantly to characteristics improvement for all tested criteria. Essential oil of oregano was more effective than black cumin oil. Further investigation will include the application of an optimized edible film with $2 \%$ oregano oil as an active packaging of dried food products.

\section{RESEARCH FUNDING}

This work is part of the project TR-31055, financed by the Ministry of Education and Science, Republic of Serbia.

\section{CONFLICT OF INTEREST}

None declared.

\section{REFERENCES}

1. Abdollahi M., Rezaei M., Farzi G., A novel active bionanocomposite film incorporating rosemary essential oil and nanoclay into chitosan. J. Food Eng., 2012, 111, 343-350.

2. Avila-Sosa R., Palou E., Jiménez Munguía M.T., Nevárez-Moorillón G.V., Navarro Cruz A.R., López-Malo A., Antifungal activity by vapour contact of essential oils added to amaranth, chitosan, or starch edible films. Int. J. Food Microbiol., 2012, $153,66-72$.

3. Benavides S., Villalobos-Carvajal R., Reyes J.E., Physical, mechanical and antibacterial properties of alginate film: effect of the crosslinking degree and oregano essential oil concentration. J. Food Eng., 2012, 110, 232-239.

4. Bigi A., Cojazzi G., Panzavolta S., Rubini K., Roveri N., Mechanical and thermal properties of gelatin films at different degrees of glutaraldehyde crosslinking. Biomaterials, 2001, 22, 763-768.

5. Bilbao-Sáinz C., Wood R.J.A.B.D.F., Williams T.G., McHugh T.H., Composite edible films based on hydroxypropyl methylcellulose reinforced with microcrystalline cellulose nanoparticles. J. Agric. Food Chem., 2010, 58, 3753-3760.
6. Bulèon A., Gallant D.J., Bouchet B., Mouille G., D'Hulst C., Kossmann J., Ball S., Starches from A to C (Chlamydomonas reinhardtii as a model microbial system to investigate the biosynthesis of the plant amylopectin crystal). Plant Physiol., 1997, 115, 949-957.

7. Burt S., Essential oils: Their antibacterial properties and potential applications in foods. Int. J. Food Microbiol., 2004, 94, 223-253.

8. Campos C.A., Gerschenson L.N., Flores S.K., Development of edible films and coatings with antimicrobial activity. Food Bioprocess Tech., 2001, 4, 849-875.

9. Chiumarelli M., Hubinger M., Stability, solubility, mechanical and barrier properties of cassava starch-Carnauba wax edible coatings to preserve fresh-cut apples. Food Hydrocolloid., 2012, 28, 59-67.

10. Fabra M.J., Talens P., Chiralt A., Water sorption isotherms and phase transitions of sodium caseinate-lipid as affected by lipid interactions. Food Hydrocolloid., 2010, 24, 384-391.

11. Falguera V., Quinterob J.P., Jimenez A., Munoz J.A., Ibarz A., Edible films and coatings: Structures, active functions and trends in their use. Trends Food Sci. Tech., 2011, 22, 292-303.

12. Fang J.M., Fowler P.A., Tomkinson J., Hill C.A.S., The preparation and characterization of a series of chemically modified potato starches. Carbohydr. Polym., 2002, 47, 245-252.

13. Ghasemlou M., Aliheidari N., Fahmi R., Shojaee-Aliabadi S., Keshavarz B., Cran M.J., Khaksar R., Physical, mechanical and barrier properties of corn starch films incorporated with plant essential oils. Carbohydr. Polym., 2013, 98, 1117-1126.

14. Ghasemlou M., Khodaiyan F., Oromiehie A., Yarmand M.S., Development and characterization of a new biodegradable edible film made from kefiran an exopolysaccharide obtained from kefir grains. Food Chem., 2011, 127, 1496-1502.

15. Gniewosz M., Krasniewska K., Woreta M., Kosakowska O., Antimicrobial activity of a pullulan-caraway essential oil coating on reduction of food microorganisms and quality in fresh baby carrot. J. Food Sci., 2013, 78, M1242-1248.

16. Goni P., Lopez P., Sanchez C., Gomez-Lus R., Becerril R., Nerin C., Antimicrobial activity in the vapour phase of a combination of cinnamon and clove essential oils. Food Chem., 2009, 116, 982-989.

17. Han J.H., Antimicrobial food packaging. 2003, in: Novel Food Packaging Techniques (ed. R. Ahvenainen). Woodhead Publishing, Cambridge, UK, pp. 50-70.

18. ISO 2528:1995. Sheet materials - Determination of water vapour transmission rate - Gravimetric (dish) method, 1995, International Organization for Standardization, 11.

19. Jiménez A., Fabra M.J., Talens P., Chiralt A., Phase transitions in starch based films containing fatty acids. Effect on water sorption and mechanical behavior. Food Hydrocolloid., 2013, 30, 408-418.

20. Jridi M., Souissi N., Mbarek A., Chadeyron G., Kammoun M., Nasri M., Comparative study of physico-mechanical and oxidant properties of edible gelatin films from the skin of cuttlefish. Int. J. Biol. Macromol., 2013, 61, 17-25.

21. Kavoosi G., Dadfar S.M.M., Mohammadi Purfard A., Mechanical, physical, antioxidant, and antimicrobial properties of gelatin films incorporated with Thymol for potential use as nano wound dressing. J. Food Sci., 2013, 78, E244-E250. 
22. Kechichian V., Ditchfield C., Veiga-Santos P., Tadini C.C., Natural antimicrobial ingredients incorporated in biodegradable films based on cassava starch. LWT - Food Sci. Technol., 2010, 43, 1088-1094.

23. Lopez O.V., Garcia M.A., Starch films from a novel (Pachyrhizus ahipa) and conventional sources: Development and characterisation. Mater. Sci. Eng. C., 2012, 32, 1931-1940.

24. Mali S., Grossmann M.V.E., Garcia M.A., Martino M.N., Zaritzky N.E., Microstructural characterization of yam starch films. Carbohydr. Polym., 2002, 50, 379-386.

25. Mali S., Grossmann M.V.E., Garcia M.A., Martino M.N., Zaritzky N.E., Effects of controlled storage on thermal, mechanical and barrier properties of plasticized films from different starch sources. J. Food Eng., 2006, 75, 453-460.

26. Mehyar G.F., Al-Ismail K., Han J.H., Chee G.W., Characterization of edible coatings consisting of pea starch, whey protein isolate, and carnauba wax and their effects on oil rancidity and sensory properties of walnuts and pine nuts. J. Food Sci., 2012, 77, E52-E59.

27. Morales F.J., Jimenez-Perez S., Free radical scavenging capacity of Maillard reaction products as related to colour and fluorescence. Food Chem., 2001, 72, 119-125.

28. Müller C.M.O., Borges Laurindo J., Yamashita F., Effect of cellulose fibers addition on the mechanical properties and water vapour barrier of starch-based films. Food Hydrocolloid., 2009, 23, 1328-1333.

29. Nanasombat S., Wimuttigosol P., Antimicrobial and antioxidant activity of spice essential oils. Food Sci. Biotechnol., 2011, 20, $45-53$.

30. Nobrega M.N., Olivato J.B., Muller C.M.O., Yamashita F., Biodegradable starch-based films containing saturated fatty acids. Polimeros - Ciencia e Tecnologia, 2012, 22, 475-480.

31. Oriani V.B., Molina G., Chiumarelli M., Pastore G.M., Hubinger M.D., Properties of cassava starch-based edible coating containing essential oils. J. Food Sci., 2014, 79, E189-E194.

32. Parker R., Ring S.G., Aspects of the physical chemistry of starch. J. Cereal. Sci., 2001, 34, 1-17.

33. Pelissari F.M., Grossmann M.V.E., Yamashita F., Pineda E.A.G., Antimicrobial, mechanical, and barrier properties of cassava starch-chitosan films incorporated with oregano essential oil. J. Agric. Food Chem., 2009, 57, 7499-7504.

34. Prior R.L., Wu X., Schaich K., Standardized methods for the determination of antioxidant capacity and phenolics in foods and dietary supplements. J. Agric. Food Chem., 2005, 53, 42904303.

35. Rodríguez M., Oses J., Ziani K., Mate J.I., Combined effect of plasticizers and surfactants on the physical properties of starch based edible films. Food Res. Int., 2006, 39, 840-846.

36. Salarbashi D., Tajik S., Ghasemlou M., Shojaee-Aliabadi S., Noghabi M.S., Khaksar R., Characterization of soluble soybean polysaccharide film incorporated essential oil intended for food packaging. Carbohydr. Polym., 2013, 98, 1127-1136.

37. Sanchez-Gonzalez L., Vargas M., Gonzalez-Martinez C., Chiralt A., Chafer M., Use of essential oils in bioactive edible coatings. Food Eng. Rev., 2011, 3, 1-16.

38. Shojaee-Aliabadi S., Hosseini H., Mohammadifar M.A., Mohammadi A., Ghasemlou M., Ojagh S.M., Hosseini S.M., Khaksaret R., Characterization of antioxidant-antimicrobial $\kappa$-carrageenan films containing Satureja hortensis essential oil. Int. J. Biol. Macromol., 2013, 52, 116-124.

39. Singh S., Das S.S., Singh G., Schuff C., de Lampasona M.P., Catalan C.A.N., Composition, in vitro antioxidant and antimicrobial activities of essential oil and oleoresins obtained from black cumin seeds. BioMed. Res. Int., 2014, 2014, Article ID 918209.

40. Singleton V.L., Orthofer R., Lamuela-Raventos R.M., Analysis of total phenols and other oxidation substrates and antioxidants by means of Folin-Ciocalteu reagent. Meth. Enzymol., 1999, 299: 152-178.

41. Souza A.C., Goto G.E.O., Mainardi J.A., Coelho A.C.V., Tadini C.C., Cassava starch composite films incorporated with cinnamon essential oil: Antimicrobial activity, microstructure, mechanical and barrier properties. LWT - Food Sci. Technol., 2013, 54, 346-352.

42. Viuda-Martos M., Ruiz-Navajas Y., Fernandez-Lopez J., Perez-Alvarez J.A., Antibacterial activity of different essential oils obtained from spices widely used in Mediterranean diet. Int. J. Food Sci. Technol., 2008, 43, 526-531.

43. Viuda-Martos M., Ruiz-Navajas Y., Fernandez-Lopez J., Perez-Alvarez J.A., Chemical composition of the essential oils obtained from some spices widely used in Mediterranean region. Acta Chim. Slov., 2007, 54, 921-926.

Submitted: 10 September 2015. Revised: 18 February 2016. Accepted: 12 April 2016. Published on-line: 31 August 2016. 
